\title{
Das Rauchen aufgeben, macht psychisch gesünder
}

\author{
Die Assoziation zwischen Zigarettenkonsum und physischen \\ Erkrankungen ist bekannt. Welche Auswirkungen das Rauchen \\ bzw. das Nichtrauchen auf die mentale Gesundheit hat, haben \\ britische Forscher um G. Taylor nun untersucht. \\ BMJ 2014; 348: g1151
}

Raucher sind kränker und haben eine kürzere Lebenserwartung als Nichtraucher. Viele Menschen wollen das Rauchen aufgeben, sind aber der Meinung, dass durch den Zigarettenkonsum emotionale Probleme, Ängste oder Stress gelindert würden. Was mit der psychischen Gesundheit passiert, wenn ein Raucher das Rauchen aufgibt, ist bislang völlig unbekannt. G. Taylor et al. gingen dieser Frage nach, indem sie eine systematische Metaanalyse von Observationsstudien durchführten. Als geeignet angesehen wurden Längsschnittstudien mit Erwachsenen, deren mentale Gesundheit untersucht wurde, bevor und mind. 6 Wochen nachdem sie mit dem Rauchen aufgehört hatten.

Insgesamt wurden 26 Studien eingeschlossen, die mit einem geeigneten Fragebogen die mentale Gesundheit hinsichtlich Angst, Depression, einer Mischung aus Angst und Depression, psychischer Lebensqualität, positiver Lebenseinstellung und Stress erfasst hatten. Mentale Gesundheits-Werte wurden 7
Wochen bis 9 Jahre nach Aufgabe des Rauchens ermittelt. Alle erfassten Parameter und psychiatrischen Zustände wurden durch das Aufgeben des Rauchens verbessert: Angst sank um 37\%, Depression um 25\%, die Kombination Angst und Depression um 31\%, Stress um 27\%. Die psychische Lebensqualität stieg um $22 \%$ und die positive Lebenseinstellung um 40\%. Die Effekte waren über alle untersuchten Patienten gleich, unabhängig davon, ob eine psychiatrische Erkrankung vorlag oder nicht. Im Hinblick auf Stimmung und Angststörungen waren die hier gemessenen Effekte gleich oder stärker als die einer antidepressiven Behandlung.

\section{Fazit}

Das Rauchen aufzugeben senkt Angst und Depression und verbessert die Lebensqualität und -einstellung. Dieser Effekt sei größer als der einer antidepressiven Behandlung, so die Autoren.

\section{Dr. Peter Pommer, Oberammergau}

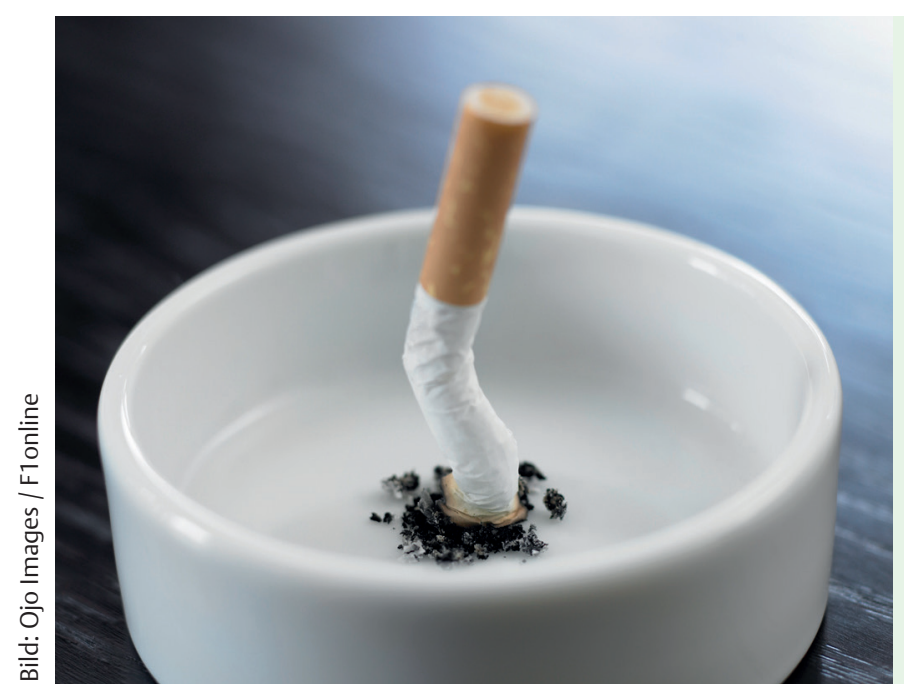

Wer mit dem Rauchen aufhört, tut nicht nur etwas für seine physische sondern auch für seine psychische Gesundheit.

Ausschreibung

Franz Redeker-Preis 2014

Das Deutsche Zentralkomitee zur Bekämpfung der Tuberkulose(DZK)schreibt jedes dritte Jahr den Franz Redeker-Preis aus. Mit dem Preis in Höhe von $2500 €$ soll die beste Arbeit auf dem Gebiet der Tuberkulosebekämpfung in Deutschland ausgezeichnet werden, die innerhalb der letzten 3 Jahre veröffentlicht wurde oder zur Veröffentlichung vorgesehen ist.

Dieser Public-Health-Preis wird 2015 auf dem Kongress des Bundesverbandes der Ärztinnen und Ärzte des Öffentlichen Gesundheitsdienstes in Rostock verliehen.

Die Bewerber werden gebeten, ihre Arbeit bis zum 31. Oktober 2014 in 4-facher Ausfertigung an folgende Adresse zu senden:

Prof. Torsten Bauer,

Deutsches Zentralkomitee zur Bekämpfung der Tuberkulose (DZK)

Lungenklinik Heckeshorn, Haus Q,

Walterhöferstr. 11,

14165 Berlin.

Weitere Informationen zu den Bewerbungsmodalitäten erhalten Sie unter der Telefonnummer: 030/81490922 oder per E-Mail: info@dzk-tuberkulose.de.

Mitteilung des Deutschen Zentralkomitees zur Bekämpfung der Tuberkulose, Berlin

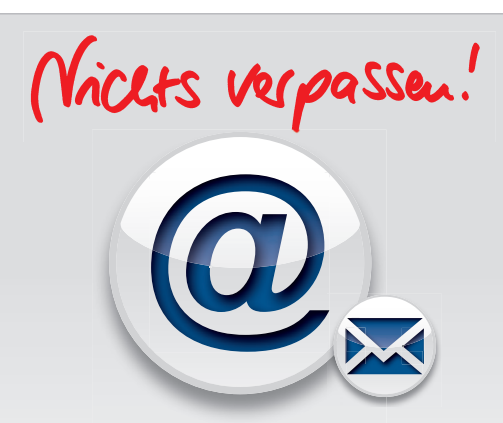

Neuerscheinungen, Veranstaltungen und Gewinnspiele

Exklusiv:

Sonderangebote und Leseproben bequem in Ihrem Postfach.

Abonnieren Sie den Thieme-Newsletter: www.thieme.de/newsletter 